\title{
Pancreatitis aguda secundaria a síndrome de asa aferente*
}

\author{
Drs. JAIME ZAMARIN M. ${ }^{1}$, ALGER RODÓ R. ${ }^{1}$, ARTURO FREDES R. ${ }^{1}$, JUAN STAMBUK M. $^{1}$ \\ 1 Hospital Clínico Fuerza Aérea de Chile, Santiago, Chile.
}

\begin{abstract}
Acute pancreatitis secondary to afferent loop syndrome. Report of one case

We report a case of a 59 years old male patient, operated in our service for an Acute Pancreatitis secondary to an Afferent Loop Syndrome. According to the literature we evaluated the low incidence of this entity, the difficulty on the clinical diagnosis, supported by the imagenologic findings and the different surgical options.
\end{abstract}

Key words: Afferent loop, pancreatitis, bowel obstruction.

\section{Resumen}

Se presenta el caso de un paciente de 59 años operado en nuestro servicio por un cuadro de pancreatitis aguda secundario a un síndrome de asa aferente agudo. Se comenta en base a la literatura la baja frecuencia en que se presenta esta entidad actualmente, su presentación clínica inespecífica, haciendo énfasis en el apoyo radiológico para llegar al diagnóstico, y las diferentes alternativas de manejo quirúrgico.

Palabras clave: Síndrome de asa aferente, pancreatitis aguda, tomografía computarizada.

\section{Introducción}

El síndrome de Asa Aferente es una complicación muy poco frecuente y se caracteriza por la obstrucción mecánica del asa desfuncionalizada o aferente que se confecciona al realizar una reconstrucción tipo Billroth II o en Y de Roux. Ocurría generalmente secundario a gastrectomías distales o subtotales que se realizaban por patología péptica gastro-duodenal. En la actualidad, el adecuado ma- nejo médico de esta patología, y la menor frecuencia de cirugía gástrica, han hecho menos frecuente esta complicación ${ }^{1,2}$.

\section{Caso Clínico}

Paciente masculino de 59 años, sin antecedentes médicos, operado el año 2002 de gastrectomía total con reconstrucción en Y de Roux por cáncer gástri-

*Recibido el 25 de Mayo de 2009 y aceptado para publicación el 22 de Agosto de 2009.

Correspondencia: Dr. Jaime Zamarin M.

Federico Froebel 1575, depto 1106, Santiago, Chile.

E-mail: jaimezamarin@hotmail.com 


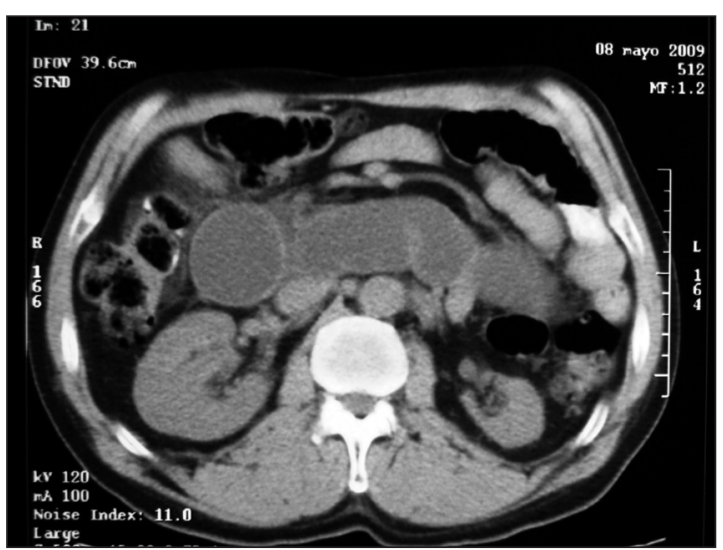

Figura 1. TAC de abdomen: Dilatación asa duodenal.

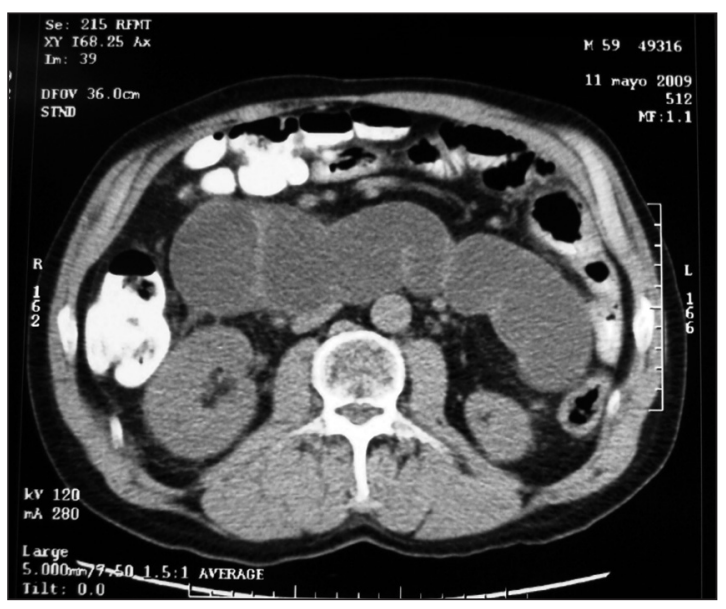

Figura 3. TAC de abdomen de Control: Mayor dilatación del asa duodenal.

co, seguido de radioterapia. Consulta en Servicio de Urgencia por cuadro de 24 horas de evolución caracterizado por dolor epigástrico irradiado a dorso, y vómitos en 2 oportunidades. Al ingreso se objetiva paciente en buenas condiciones generales sin alteración al examen físico general, pero con dolor en epigastrio a la palpación superficial, sin signos peritoneales. Se realiza estudio de laboratorio pesquisándose amilasa de $160 \mathrm{mg} / \mathrm{dl}$ y lipasa de 220 $\mathrm{mg} / \mathrm{dl}$, por lo que se hospitaliza con diagnóstico de pancreatitis aguda leve, sin claro agente etiológico, dado que las pruebas hepáticas eran normales y no se tenía el antecedente de colecistectomía en cirugía previa.

La ecotomografía no logra evaluar la vía biliar por gran distensión de asas de intestino, la tomografía computarizada (TAC) demostró dilatación de asa

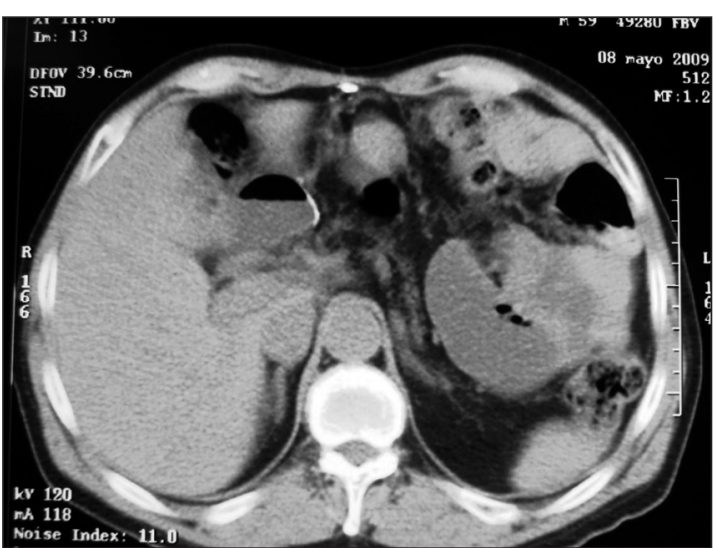

Figura 2. TAC de abdomen: Páncreas atrófico.

duodeno-yeyunal, páncreas atrófico, colecistectomizado. Figuras 1 y 2.

Se plantea la duda diagnóstica entre una pancreatitis aguda con dilatación de asa centinela, o síndrome de asa aferente con pancreatitis aguda secundaria. Dada la buena evolución clínica se decide manejo conservador y observación.

Al día siguiente se controlan exámenes destacando leucocitos, PCR y pruebas hepáticas normales, pero con alza de amilasa de $743 \mathrm{mg} / \mathrm{dl}$ y lipasa de $548 \mathrm{mg} / \mathrm{dl}$. Se asume que el cuadro sería secundario a pancreatitis aguda y se realiza nuevo estudio con TAC a las 72 horas, el que demuestra, mayor dilatación del asa aferente, con compromiso inflamatorio de su meso. Figura 3. Los exámenes de control muestran bilirrubina total de $7,7 \mathrm{mg} / \mathrm{dl}$, transaminasas y fosfatasas alcalinas de patrón colestásico. Dado lo anterior cambia enfoque diagnóstico y el cuadro se cataloga como síndrome de asa aferente agudo, por lo que se decide laparotomía exploradora.

Se realiza laparotomía media supra e infra umbilical, encontrando gran dilatación del asa aferente, sin compromiso vascular, secundario a brida gruesa ubicada a $40 \mathrm{~cm}$ bajo ángulo de Treitz, hacia proximal de la anastomosis yeyuno-yeyunal. Se realiza sección de ésta y se resuelve la obstrucción.

El paciente evoluciona favorablemente siendo dado de alta al cuarto día postoperatorio.

\section{Discusión}

El síndrome de asa aferente se produce en aproximadamente $1 \%$ de los pacientes sometidos a un Billroth $\mathrm{II}^{3}$. A esta baja incidencia se agrega la disminución en los últimos 25 años de la cirugía gástrica por patología benigna, lo que ha determinado que esta entidad se presente en forma casi anec- 
dótica. Su presentación clínica es muy inespecífica, siendo prácticamente insospechable cuando ésta se presenta en forma crónica. El cuadro agudo si bien es más florido, requiere un gran índice de sospecha, ya que en general el único hallazgo clínico es el dolor abdominal. Por lo anterior, se observa una alta tasa de mortalidad por esta patología $(30-50 \%)^{3}$, ya que el diagnóstico es tardío, haciéndose en muchos casos cuando se ha producido una peritonitis biliar secundaria a la rotura del asa. Por esta razón, tal como aconteció en este caso, la radiología juega un rol indispensable y permite realizar un diagnóstico oportuno, antes de que se presenten las complicaciones.

La relación de la obstrucción del asa aferente con pancreatitis aguda ha sido observada y presentada en otros reportes de caso internacionales ${ }^{4-7}$. La fisiopatología de este proceso sería similar a la producida en la pancreatitis biliar; la ectasia biliar del asa aferente provoca hipertensión a ese nivel, que se transmite hacia la vía biliar y el conducto de Wirsung, desencadenando una respuesta inflamatoria en la glándula pancreática con las consecuencias ampliamente conocidas?

Dada la infrecuente presentación de esta entidad, los reportes en cuanto a las distintas opciones de manejo quirúrgico se encuentran en trabajos antiguos (1960-1970) ${ }^{5}$; existen variadas causas que pueden ocasionar este cuadro, por lo que la estrategia quirúrgica debe ir enfocada en la resolución particular de cada una de ellas. En el caso de esta comunicación fue necesaria la simple resección de una brida, sin embargo, y como se detalla en la literatura, la principal técnica a utilizar es la anastomosis derivativa entre el asa aferente y eferente latero-lateral.

\section{Referencias}

1. Burkhalter E. Incidence of gastrectomy in United States army hospitals worldwide from 1975 to 1985 . Am J Gastroenterol 1988; 83: 1231-1234.

2. Paimela H, Tuompo P, Perakyl T, Saario I, Hockerstedt K, Kivilaakso E. Peptic ulcer surgery during the H2receptor antagonist era: a population-based epidemiological study of ulcer surgery in Helsinki from 1972 to 1987. Br J Surg 1991; 78: 28-31.

3. Sawyer M, Decker R. Afferent Loop Syndrome. Updated: Nov 2006. Emedicine, Disponible en: www. emedicine.medscape.com (Consultado el 15 de Mayo de 2009).

4. Pérez-Holanda S, Tojo S, Urdiales G. Ictericia secundaria a vólvulo de asa aferente del Bilroth II. Rev. Esp. Enferm. Dig 2007; 99: 123-126.

5. Hinshaw D, Carter R, Baker H. Postgastrectomy Afferent Loop Obstruction Simulating Acute Pancreatitis. Ann Surg 1960; 151: 600-604.

6. Días A. Biliary stone causing afferent loop syndrome and pancreatitis. World J Gastroenterol 2006; 126: 229 231.

7. Mithofer K, Warshaw A. Recurrent acute pancreatitis caused by afferent loop stricture after gastrectomy. Arch Surg 1996; 131: 561-565. 